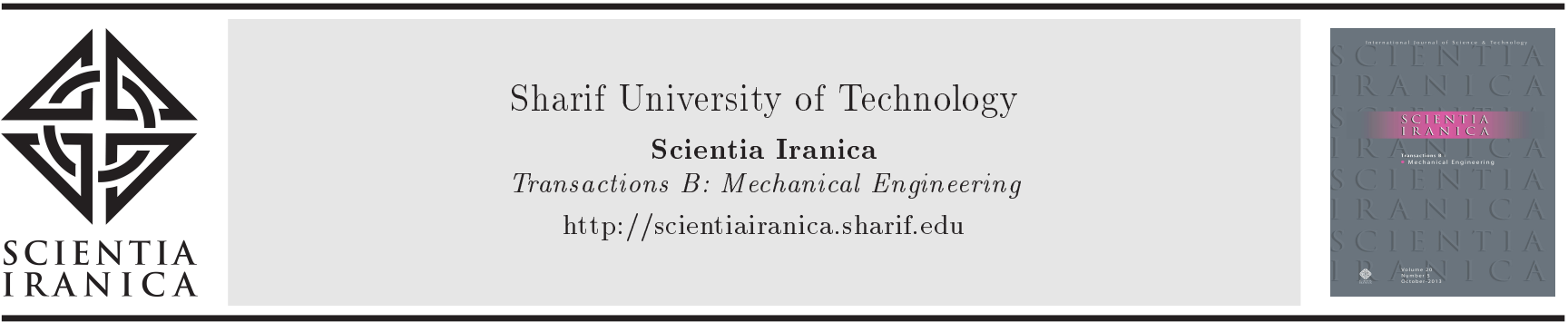

\title{
Design of conformal cooling channels by numerical methods in a metal mold and calculation of exergy destruction in channels
}

\author{
A. Bolattürk, O. İpek, K. Kurtuluş*, and M. Kan \\ Department of Mechanical Engineering, Süleyman Demirel University, Isparta, Turkey.
}

Received 24 December 2017; received in revised form 2 July 2018; accepted 18 August 2018

\section{KEYWORDS}

Metal mold;

Exergy destruction;

Cooling channel

design.

\begin{abstract}
Shorter cycle times, better product quality, and less product outage can be achieved with faster cooling. However, mold cooling channels can only be made in linear directions and limited forms via classical manufacturing methods. Therefore, they limit the performance of mold cooling. Developed in recent years, additive manufacturing technologies are capable of building complex geometries and monoblock 3D products. With this technology at hand, it is possible to produce metal molds with conformal cooling channels in different forms that are capable of qualified cooling. In this study, conformal cooling channels were designed in order to achieve optimum cooling in monoblock permanent mold. In this study, CFD (Computational Fluid Dynamic) analyses are performed in steady state conditions for designed conformal cooling channels and classical cooling channel mold. Pressure drops, cooling channel outlet temperatures, and exergy destructions are calculated based on the flow velocity rate in channels. The numerical investigations of the cooling process have shown that approximately cooling performance of $5 \%$ or higher can be achieved with conformal cooling channels. However, pressure drop in the conformal cooling is observed to be higher than classical cooling channel. In addition, exergy destruction in the conformal cooling channel is approximately $12 \%$ greater than that in the classical cooling channel.
\end{abstract}

(C) 2019 Sharif University of Technology. All rights reserved.

\section{Introduction}

Cooling process in metal molds is one of the important factors in the solidification of liquid metal. Molding defects such as hot spot defects and distortion occur in the casting products when cooling is not uniform. Conversely, qualified and faster cooling affects product quality positively. With conventional manufacturing methods, mold cooling channels can only be made in linear directions and circular cross-sections. This limits

\footnotetext{
*. Corresponding author.

E-mail address: karanikurtulus@sdu.edu.tr (K. Kurtuluş)
}

doi: $10.24200 /$ sci. 2018.50090 .1502 mold cooling performance [1]. There are studies in the literature about metal molding techniques and cooling channel design. The cooling performance of hot extrusion dies with conformal cooling channels produced by the additive manufacturing method was examined [2]. The increase of the production speed up to $300 \%$ was observed with the conformal cooling channel mold compared to the standard cooling channel mold. The cycle time in molding affects product cost and quality. It was observed that the shorter the cycle time, the higher the homogeneous temperature distribution and, thus, the fewer the component distortions. Therefore, better product quality was obtained in injection molds with conformal cooling channels [3-9]. The fact that the cost of production is high in metal molds produced 
with the additive manufacturing method makes it necessary to produce the conformal cooling channel design with the desired performance. By using the finite element method, the cooling performance of mold cooling channels and the solidification process of liquid metal can be simulated. Numerical studies have been investigated for increasing the cooling performance by decreasing the solidification time through the conformal cooling channel [10-12]. A conformal cooling channel for plastic injection mold was designed [1]. The study was conducted numerically and experimentally. Numerical and experimental investigations revealed a shorter cycle time by $12.8 \%$ with conformal cooling channels. In addition, Park and Dang [9] developed conformal cooling channel for plastic injection mold. The study results showed a $30 \%$ shorter cycle time with conformal cooling channels.

Friction losses, heat transfer due to temperature difference, and rapid expansion and compression are causes of the loss of exergy in a system [13-15]. The molten metal heat is transferred through the cooling channels. The heat transfer between the molten metal and the cooling channels is similar to the working principle of heat exchangers. There are many studies in the literature about the loss of exergy in heat exchangers. However, studies on loss of exergy in metal mold cooling channels are very few in literature. In order to determine the optimum working conditions of the heat exchangers or thermodynamic cycles and reduce exergy destruction, the parameters such as fluid velocity, pressure drop, and temperature distribution were examined by researchers. They emphasized that the exergy destruction was reduced by improving these parameters [16-19].

With the additive manufacturing technology developed in recent years, products can be manufactured in complex geometries and compact structures. In this study, cooling channels in a metal mold are designed in different geometries that cannot be produced by conventional manufacturing methods. Two different conformal cooling channel molds are designed and compared with standard cooling channel mold numerically in the steady state conditions. Heat transfer rates, exergy destructions, and pressure drops at different flow rates are calculated for each channel.

\section{Numerical modelling and mathematical method}

In this study, a permanent mold (Figure 1) is modeled for gravity die casting. The mold casting geometry is an exhaust valve of a gasoline internal combustion engine. The hydrodynamic and thermal behavior of the mold cooling channels is investigated numerically. The mold with a conformal cooling channel will be produced by the SLM (Selective Laser Melting) method

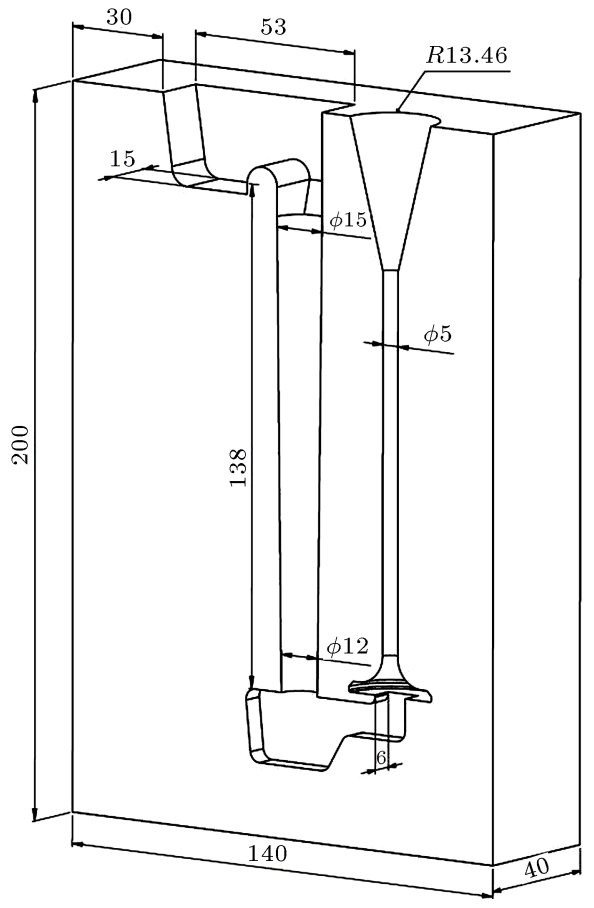

Figure 1. The solid model of metal mold symmetry part.

from stainless steel $316 \mathrm{~L}$ powder. Nitriding will be applied to prevent molten aluminum damaging the mold surface [20]. Mold consists of two symmetry parts and simulations are conducted on a symmetrical part.

\subsection{Mathematical model}

In the present work, exergy destructions in the cooling channels are calculated by assuming the melt temperature at $973 \mathrm{~K}[21]$. The theoretical value, $\dot{Q}_{A l}$, is calculated, assuming that the molten metal Al-A413 has cooled from $973 \mathrm{~K}$ to $623 \mathrm{~K}$ in 50 seconds. Predicted cycle time is 50 seconds for the selected casting piece based on industrial experience. $\dot{Q}_{A l}$ can be written as in Eq. (1). By using this value, the heat flux, which is in contact with mold surface, was calculated.

$$
\dot{Q}_{A l}=Q_{A l} / d t
$$

The heat in the solidification of molten metal is the sum of sensible and latent heat represented as in Eq. (2):

$$
Q_{A l}=Q_{\text {sensible }}+Q_{\text {latent }} .
$$

In this study, $L H=500000 \mathrm{~J} / \mathrm{kg}$ is assumed, and sensible and latent heat can be written as in Eqs. (3) and (4):

$$
\begin{aligned}
& Q_{\text {sensible }}=m_{A l} \cdot c_{A l} \cdot \Delta T, \\
& Q_{\text {latent }}=m_{A l} \cdot L H .
\end{aligned}
$$

The heat transferred to the cooling channel is represented as in Eq. (5):

$$
\dot{Q}_{\text {channel }}=\dot{m}_{\text {oil }} \cdot c_{p} \cdot\left(T_{\text {outlet }}-T_{\text {inlet }}\right) .
$$




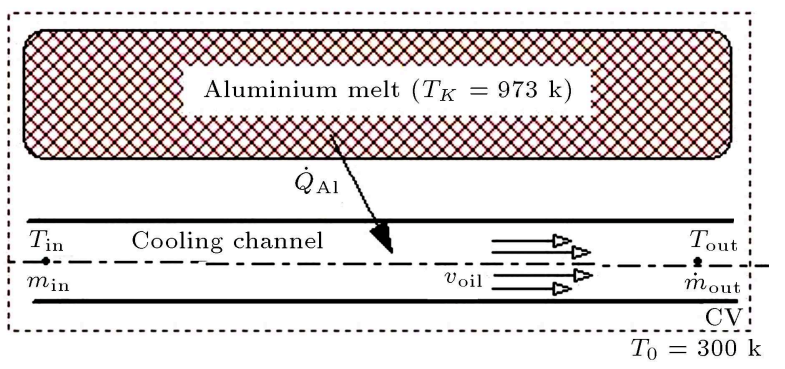

Figure 2. The assumptions in the mold cooling channels of heat transfer mechanism.

Here, the mass flow rate depends on the velocity in thehydraulic diameters of the designed cooling channels. The mass flow rate is given as follows:

$$
\dot{m}_{\text {oil }}=\rho_{\text {oil }} \cdot V \cdot A_{c} .
$$

Hydraulic diameter in rectangular, triangular, or any profile channels is given as follows:

$$
D_{h}=\frac{4 A_{c}}{P_{w}},
$$

where $A_{c}$ is the cross-sectional area, and $P_{w}$ is the wetted perimeter.

Figure 2 shows the heat transfer mechanism with certain assumptions concerning the mold cooling channels. The cooling channel is a steady-flow process since there is no change in time and cooling oil inlet temperature is $573 \mathrm{~K}$ [22]. Entropy generation can be written as in Eq. (8):

$$
\begin{aligned}
\sum \frac{\dot{Q}_{A l}}{T_{k}} & +\sum \dot{m}_{\text {oil,inlet }} s_{\text {inlet }} \\
& -\sum \dot{m}_{\text {oil,outlet }} s_{\text {outlet }}+\dot{S}_{g e n}=d S_{C V} / d t
\end{aligned}
$$

where $T_{k}(973 \mathrm{~K})$ is the source temperature of the heat given to the cooling channel by the aluminum melt, and $\dot{m}$ is the mass flow rate $(\mathrm{kg} / \mathrm{s})$ of cooling oil. The right side of Eq. (8) is zero because of the steady-flow process. The entropy change in the cooling channel is obtained as follows:

$$
s_{\text {in }}-s_{\text {out }}=c_{p, \text { oil }} \ln \left(T_{\text {in }} / T_{\text {out }}\right) .
$$

Exergy destruction of the system is given in Eq. (10), and $T_{0}$ is the ambient temperature and assumed to be $300 \mathrm{~K}$.

$$
\dot{E}_{d e s}=T_{0} \dot{S}_{g e n}
$$

\subsection{Numerical modeling}

Computational domains of the analyzed cooling channels (Standard Channel (SC), Curved Channel (CC), and Spherical Fin Channel (SFC)) are designed (Figure 3 ). The tetrahedral mesh structure is provided for CFD analysis. Mesh parameters that are used in the simulation process are given in Table 1. For designed models, there are $1.023 .000,1.148 .000$, and 1.356 .000 mesh elements in SC, CC, and SFC, respectively, as can be seen in Table 1. Hydraulic diameters and hydraulic diameter cross-sectional areas of the designed cooling channels are shown in Table 2. For each cooling channel, the channel exit temperatures and pressure drops are calculated by changing the cooling oil velocity of the hydraulic cross-sectional areas to $0.2-2 \mathrm{~m} / \mathrm{s}$ range [23].

Analyses are performed using ANSYS-FLUENT 16.1 software [24]. In Figure 4, the boundary conditions are depicted. The numerical modeling parameters used in solutions are presented in Table 3 . The heat transfer oil specifications of "Petro-therm" brand name are used as refrigerant in the cooling channels. The thermal properties of heat transfer oil used in numerical analysis are shown in Table 4. Mold material GGG 50 ductile cast iron is used for SC mold material in the analysis. For CC and SFC, the thermal properties of mold stainless steel $316 \mathrm{~L}$ are applied in the analysis. The thermal properties of mold materials used in numerical analysis are presented in Table 5 .

Table 1. Mesh parameters used in simulations.

\begin{tabular}{lccc}
\hline & SC & CC & SFC \\
\hline Mesh element number & 1023000 & 1148000 & 1356000 \\
Aspect ratio & 1.841 & 1.8468 & 1.8646 \\
Jakobian ratio & 1.0132 & 1.0 & 1.0 \\
Skewness & 0.23437 & 0.22976 & 0.23697 \\
\hline
\end{tabular}

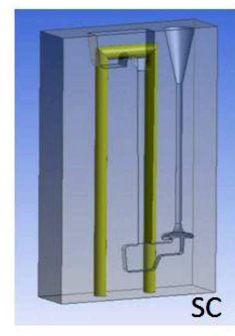

SC
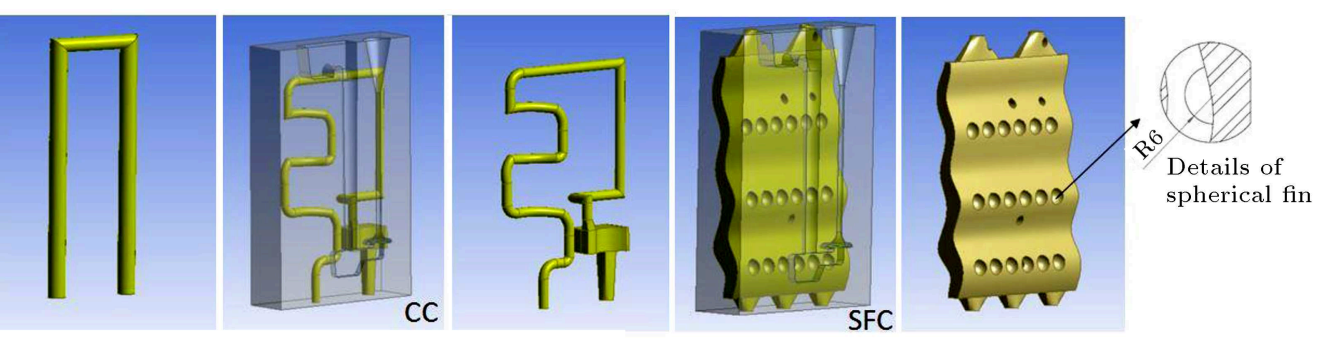

Figure 3. Computational domains of the analyzed cooling channels. 
Table 2. Hydraulic diameters and hydraulic diameter cross-sectional areas of the designed cooling channels.

\begin{tabular}{lcc}
\hline $\begin{array}{l}\text { Cooling } \\
\text { channel }\end{array}$ & $\begin{array}{c}\text { Hydraulic } \\
\text { ciameter }(\mathbf{m})\end{array}$ & $\begin{array}{c}\text { Hydraulic diameter } \\
\text { cross-sectional area } \\
\left.\mathbf{( m}^{\mathbf{2}}\right)\end{array}$ \\
\hline Standard Channel (SC) & 0.01 & 0.00007854 \\
Curled Channel (CC) & 0.009437 & 0.00003848 \\
Spherical Fin Channel (SFC) & 0.015 & 0.00096 \\
\hline
\end{tabular}

Table 3. Numerical modeling parameters used in solutions.

\begin{tabular}{ll}
\hline Simulation condition & Steady-state \\
Solver type & Pressure based \\
Mesh structure & Tetrahedral \\
Turbulence model & RNG-enhanced wall treatment stand. $k-\varepsilon$ Turbulance Model \\
Wall-turbulence interaction & Standard wall-function \\
Speed-pressure interaction & Simple algorithm \\
Decomposition method & Second order upwind \\
\hline
\end{tabular}

Table 4. Thermal properties of heat transfer oil used in numerical analysis.

\begin{tabular}{|c|c|c|c|c|c|}
\hline $\begin{array}{l}\text { Temperature } \\
\text { (K) }\end{array}$ & $\begin{array}{l}\text { Density } \\
\left(\mathrm{kg} / \mathrm{m}^{\mathbf{3}}\right)\end{array}$ & $\begin{array}{c}\text { Specific } \\
\text { heat }(\mathrm{J} / \mathrm{kgK})\end{array}$ & $\begin{array}{c}\text { Thermal } \\
\text { conductivity } \\
(\mathrm{W} / \mathrm{mK})\end{array}$ & $\begin{array}{c}\text { Temperature } \\
\text { (K) }\end{array}$ & $\begin{array}{l}\text { Viscosity } \\
(\mathrm{kg} / \mathrm{ms})\end{array}$ \\
\hline 288 & 869 & 1890 & 0.143 & 313 & $3.07 \times 10^{-3}$ \\
\hline 311 & 855 & 1970 & 0.142 & 373 & $4.8735 \times 10^{-4}$ \\
\hline 533 & 714 & 2690 & 0.13 & 598 & $4.753 \times 10^{-5}$ \\
\hline 559 & 679 & 2880 & 0.128 & - & - \\
\hline
\end{tabular}

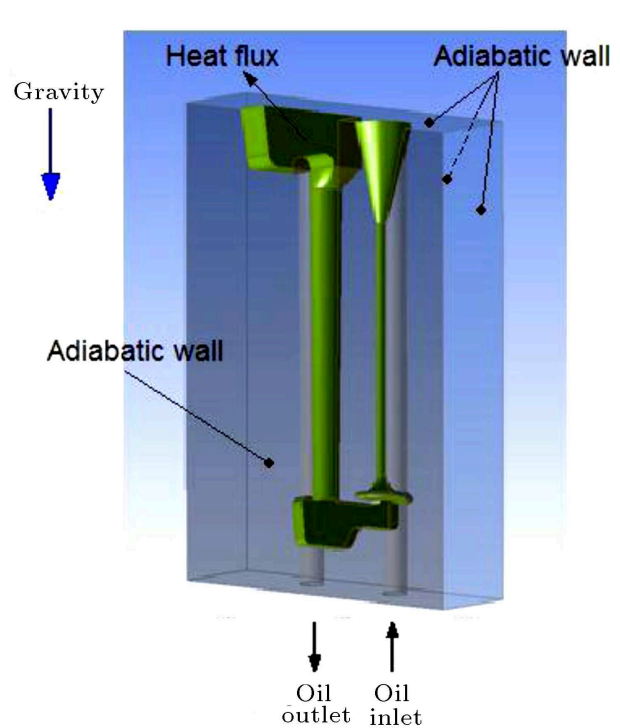

Figure 4. Boundary conditions used for the analyzed mold configuration.

\section{Numerical results}

\subsection{Validation of numerical analysis}

In this study, a permanent mold is modeled for gravity die casting. The study has not been conducted experimentally; however, it is not possible to find studies with a similar geometry like this study in the literature. Therefore, the validation of the numerical results was performed by Imran et al. [23]. They practiced similar methods and boundary conditions in this study. Experiments were conducted to determine the effect of water mass flow rate and heat load on thermal and hydraulic performances of the heat exchanger. Considering the full geometry of the heat exchanger (configuration a), all presumptions, and boundary conditions of the system, the modeling and simulation of that experimental study were conducted. The comparison was carried out at the base plate temperature and pressure drop of the channels. In Figure 5, the results of different mass flow rates of working fluid for the study of Imran et al. [23] and the current study are compared to base temperature. The deviation between the numerical and the experimental results is found 10\%. Figure 6 demonstrates the comparison of numerical and experimental results of the pressure drop for different mass flow rates of the working fluid. The difference between numerical and experimental results is observed to be $8 \%$. The difference between the pressure drop of the current research and the study of Imran et al. [23] is observed 
Table 5. Thermal properties of mold materials used in numerical analysis.

\begin{tabular}{ccccc}
\hline Mold type & Mold material & $\begin{array}{c}\text { Density } \\
\left(\mathbf{k g} / \mathbf{m}^{3}\right)\end{array}$ & $\begin{array}{c}\text { Specific } \\
\text { heat }(\mathbf{J} / \mathbf{k g K})\end{array}$ & $\begin{array}{c}\text { Thermal } \\
\text { conductivity } \\
(\mathbf{W} / \mathbf{m K})\end{array}$ \\
\hline SC & $\begin{array}{c}\text { GGG 50 ductile } \\
\text { cast iron }\end{array}$ & 7200 & 500 & 35.2 \\
CC and SFC & Stainless steel 316 L & 7990 & 550 & 16.3 \\
\hline
\end{tabular}

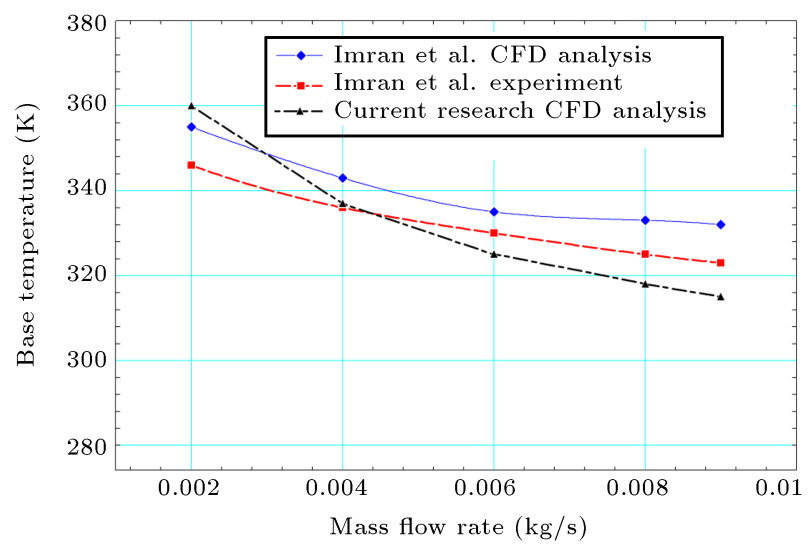

Figure 5. Comparison of Imran et al. [23] and the current study results for base temperature.

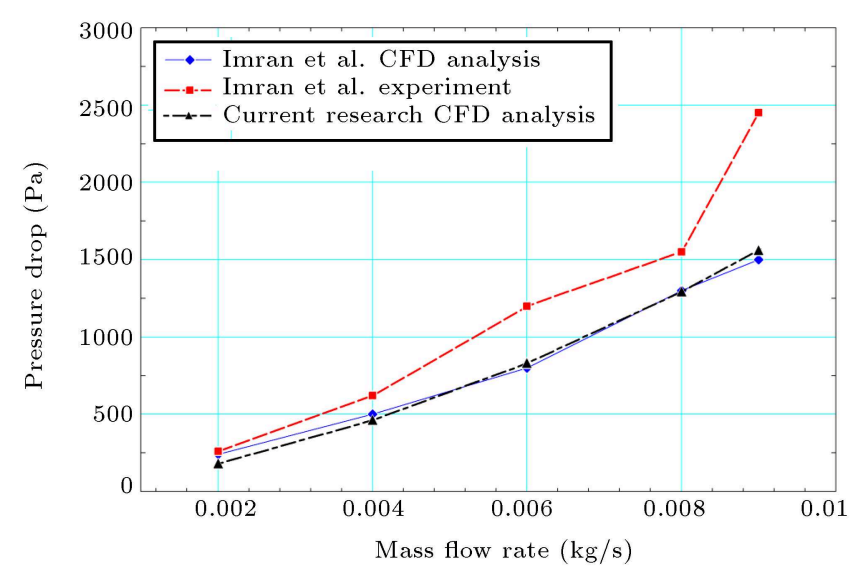

Figure 6. Comparison of Imran et al. [23] and the current study results for pressure drop.

to be of almost the same value. It is observed that there is consistency between numerical and experimental data.

\subsection{Numerical simulations results}

In Figure $7(\mathrm{a})$, the comparison of heat transfer rate and pressure drops of SC, CC, and SFC based on flow rates is presented. SFC transfers more heat than $\mathrm{CC}$ and SC. As the fluid velocity increases, there is no significant change in the amount of heat transferred in the SFC, while there is a decrease in SC and CC. As the velocity increases, the pressure drop is around 1-4 $\mathrm{kPa}$ in $\mathrm{SC}$. In $\mathrm{SFC}$, this value is up to approximately $50 \mathrm{kPa}$.
Exergy destruction is calculated using the Engineering Equation Solver (EES) software [25]. In Figure 7(b), the comparison of channel outlet temperatures and exergy losses of SC, CC, and SFC based on flow rates is presented. For SC, the exergy destruction increases up to $0.6 \mathrm{~m} / \mathrm{s}$ in value and, then, decreases as the speed increases. The outlet temperature of the cooling oil decreases from $625 \mathrm{~K}$ to $580 \mathrm{~K}$ as the velocity increases. Exergy destruction increases up to $1 \mathrm{~m} / \mathrm{s}$ for $\mathrm{CC}$ and, then, decreases. Exergy destruction changes between $0.286-0.332 \mathrm{~kW}$ and is similar to SC. The outlet temperature of the cooling oil decreases from $680 \mathrm{~K}$ to $582 \mathrm{~K}$ as the velocity increases. The exergy destruction for SFC fluctuates around $0.37 \mathrm{~kW}$. As the speed increases, a significant change in the destruction of the exergy for this channel does not occur. The outlet temperature of the cooling oil decreases from $577.5 \mathrm{~K}$ to $573.5 \mathrm{~K}$ as the velocity increases. The difference between the inlet temperature and the outlet temperature of the cooling channel is $4 \mathrm{~K}$, which is in a small temperature range.

\section{Conclusion}

In the present work, CFD analyses were performed in the steady state conditions for designed cooling channels and classical cooling channel mold. Pressure drops, cooling channel outlet temperatures, and exergy destructions were calculated based on the flow velocity rate in channels. Numerical analysis investigations revealed that, for a $1-\mathrm{m} / \mathrm{s}$ reference velocity, the heat transfer rate in SFC was $5 \%$ higher than SC. Accordingly, heat transfer rate increased as the cycle time decreased. These results are in accordance with existing literature [1-9]. For $1 \mathrm{~m} / \mathrm{s}$ velocity rate, the SC and SFC required pump power of $0.157 \mathrm{~W}$ and 11.7 W, respectively. On the other hand, a higher heat transfer rate of $40 \mathrm{~W}$ was obtained by SFC. However, as the flow rate in hydraulic diameters increased, the pressure drop was observed to be enormous in this channel. As the flow rate decreased in SC and $\mathrm{CC}$, the temperature difference between $T_{\text {outlet }}$ and $T_{\text {inlet }}$ was higher than that in SFC. Numerical calculations showed that the exergy destruction in the SFC occurred almost constantly with small fluctuations and was $12 \%$ higher than the SC. The decrease of the exergy 


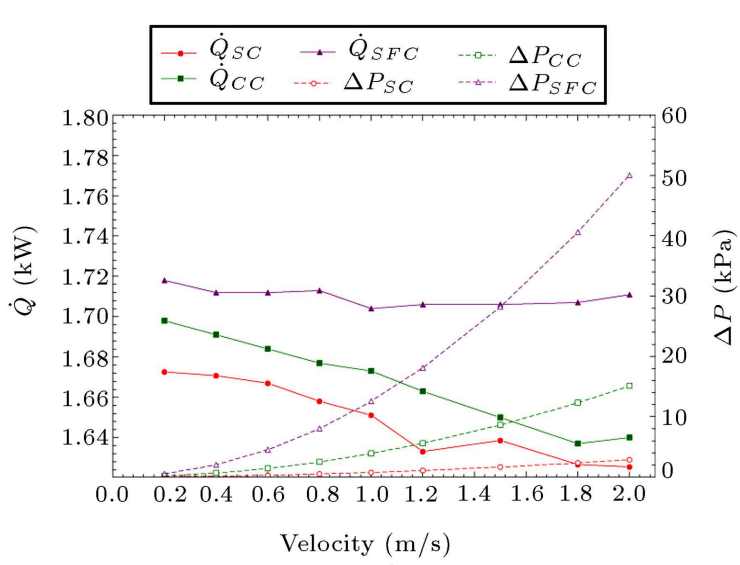

(a)

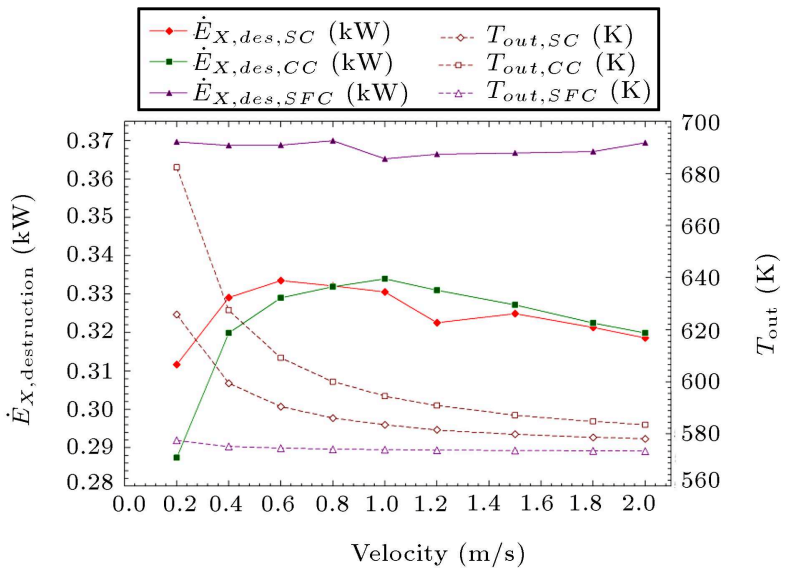

(b)

Figure 7. (a) Comparison of heat transfer rate and pressure drops of SC, CC, and SFC based on flow rates. (b) Comparison of channel outlet temperatures and exergy losses of SC, CC, and SFC based on flow rates.

destruction could improve the efficiency and increase the cooling channel heat transfer rate. The design of the cooling channel can be developed in future studies.

\section{Acknowledgment}

The financial supports for this research, from the Scientific Research Projects Office (BAP) of Süleyman Demirel University (Project No: FDK-2018-5597), Turkey.

\section{References}

1. Hsu, F.H., Wang, K., Huang, C.T., and Chang, R.Y. "Investigation on conformal cooling system design in injection molding", Advances in Production Engineering \& Management, 8(2), pp. 107-115 (2013).

2. Hölker, R. Haase, M. Khalifa, N.B., and Takkaya, A. E. "Hot extrusion dies with conformal cooling channels produced by additive manufacturing", Aluminum Two Thousand World Congress and International Conference on Extrusion and Benchmark ICEB, pp. 48384846 (2015).

3. Sachs, E., Wylonis, E. Allen, S. Cima, M., and Guo, $\mathrm{H}$. "Production of injection moulding tooling with conformal cooling channels using the three dimensional printing process", Polymer Engineering and Science, 40(5), pp. 1237-1247 (2000).

4. Eimsa-ard, K. and Wannisorn, K. "Conformal bubbler cooling for molds by metal deposition process", Computer-Aided Design, 69, pp. 126-133 (2015).

5. Wang, Y., Yu, K.M., and Wang, C.C.L. "Spiral and conformal cooling in plastic injection molding", Computer-Aided Design, 63, pp. 1-11 (2015).

6. Vojnová, E. "The benefits of a conforming cooling systems the molds in injection moulding process", Procedia Engineering, 149, pp. 535-543 (2016).
7. Venkatesh, G.Y., Ravi, K., and Raghavendra, G. "Comparison of straight line to conformal cooling channel in injection molding", Materials Today: Proceedings, 4(2), pp. 1167-1173 (2017).

8. Jahan, A.S. and Mounayri, H. "Optimal conformal cooling channels in 3D printed dies for plastic injection molding", Procedia Manufacturing, 5, pp. 888-900 (2016).

9. Park, H. and Dang, X.P. "Development of a smart plastic injection mold with conformal cooling channels", Procedia Manufacturing, 10, pp. 48-59 (2017).

10. Wang, G., Zhao, G., Li, H., and Guan, Y. "Multiobjective optimization design of the heating/cooling channels of the steam-heating rapid thermal response mold using particle swarm optimization", Int. J. of Thermal Science, 50, pp. 790-802 (2011).

11. Franke, M.M., Hilbinger, R.M., Lohmüller, A., and Singer, R.F. "The effect of liquid metal cooling on thermal gradients in directional solidification of super alloys: Thermal analysis", Journal of Material Processing Technology, 213, pp. 2081-2088 (2013).

12. Furumoto, T., Ueda, T., Amino, T., Ksunoki, D., Hosokowa, A., and Tanaka, T. "Finishing performance of cooling channel with face protuberance inside the molding die", Journal of Material Processing Technology, 212, pp. 2154-2160 (2012). DOI: 10.1016/j.jmatprotec.2012.05.016

13. Khairul, M.A., Alim, M.A., Mahbubul, I.M., Saidur, R., Hepbasli, A., and Hossain, A. "Heat transfer performance and exergy analyses of a corrugated plate heat exchanger using metal oxide nanofluids", International Communications in Heat and Mass Transfer, 50, pp. 8-14 (2014).

14. Dizaji, H.S., Jafarmadar, S., and Asaadi, S. "Experimental exergy analysis for shell and tube heat exchanger made of corrugated shell and corrugated tube", Experimental Thermal and Fluid Science, 81, pp. $475-481$ (2017). 
15. Ipek, O., Kan, M., and Gurel, B. "Examination of different heat exchangers and the thermal activities of different designs", Acta Physica Polonica A, 132(3), pp. 580-583 (2017).

16. Kan, M., Ipek, O., and Gurel, B. "Plate heat exchangers as a compact design and optimization of different channel angles", Acta Physica Polonica A, 128(2B), pp. B-49_B-52 (2015).

17. Karaail, R. and Öztürk, I. T. "Thermoeconomic analyses of steam injected gas turbine cogeneration cycles", Acta Physica Polonica A, 128(2B), pp. B-279_B-281 (2015).

18. Zehtabiyan, R.N., Damirci, D.S., Fazel, Z.M.H., and Saffar, A.M. "Generalized heat transfer and entropy generation of stratified air-water flow in entrance of a mini-channel", Scientia Iranica, B, 24(5), pp. 24062417 (2017).

19. Nouri, B.A. and Seyyed, H.M.H. "Numerical analysis of thermally developing turbulent flow in partially filled porous pipes", Scientia Iranica, B, 22(3), pp. 835-843 (2015).

20. Altinsoy, İ., Çelebi Efe, G.F., Yener, T., önder, K.G., and Bindal, C. "Effect of double stage nitriding on 34CrAlNi7-10 nitriding steel", Acta Physica Polonica A, 132, pp. 663-666 (2017).

21. Arunkumar, S., Rao, K.S., and Kumar, T.P. "Spatial variation of heat flux at the metal-mold interface due to mold filling effects in gravity die-casting", Int. J. of Heat and Mass Transfer, 51(11), pp. 2676-2685 (2008).

22. Hallam, C.P. and Griffiths, W.D. "A model of the interfacial heat-transfer coefficient for the aluminum gravity die-casting process", Metallurgical and Materials Transactions B, 35(4), pp. 721-733 (2004).

23. Imran, A.A., Nabeel, S.M., and Hayder, M.J. "Numerical and experimental investigation of heat transfer in liquid cooling serpentine mini-channel heat sink with different new configuration models", Thermal Science and Engineering Progress, 6, pp. 128-139 (2018).

24. Fluent, Version 16.1 User's Guide, Fluent Inc., Lebanon (NH) (2016).
25. Klein, S.A. "Engineering Equation Solver (EES)", Academic Commercial V8.208.F-Chart Software, www.fChart.com (2008).

\section{Biographies}

Ali Bolattürk is a Professor at the Department of Mechanical Engineering at Süleyman Demirel University, Isparta, Turkey. He received his BSc and MSc degrees from Mechanical Engineering at Akdeniz University in 1990 and 1992, respectively. He has been teaching since then. His research interests are thermodynamics, heat transfer, exergy, and exergoeconomic analysis of the thermodynamic systems.

Osman Ipek is a Professor at the Department of Mechanical Engineering in Mechanical Engineering at Süleyman Demirel University. He received his BSc and MSc degrees from Akdeniz University, Antalya, Turkey in 1986 and 1988, respectively. His main researches interests focus on heat exchangers heat transfer enhancement, fluid mechanics, thermodynamics, and energy.

Karani Kurtuluş received his BSc and MSc degrees from Mechanical Engineering at Süleyman Demirel University in 2011 and 2014, respectively. $\mathrm{He}$ is currently a PhD Candidate in Mechanical Engineering and a Research Assistant at Süleyman Demirel University. His research interests are heat transfer enhancement, exergy and exergoeconomic analysis of the thermodynamic systems, Computational Fluid Dynamics (CFD), and solidification-melting analysis.

Mehmet Kan received his BSc from Mechanical Engineering at Mustafa Kemal University in 2009 and MSc degree from Mechanical Engineering at Süleyman Demirel University in 2014. He is currently a PhD Candidate in Mechanical Engineering and a Research Assistant at Süleyman Demirel University. His research interests include heat transfer enhancement, fluid mechanics, thermodynamics, energy, Computational Fluid Dynamics (CFD), and solidificationmelting analysis. 